\title{
Indebtedness and Unemployment: A Durable Relationship
}

\author{
Tore Ellingsen* Steinar Holden** \\ Working Papers in Economics and Finance No 186 \\ August 1997
}

\begin{abstract}
Within a simple formal model, we show that there is a link between workers' consumption patterns and their preferred real wage. A large budget share of illiquid durable consumption goods (such as houses and cars) makes workers more willing to accept a low wage in order to reduce the probability of unemployment, but less willing to lower the real wage if labor demand unexpectedly falls. Moreover, as long as durable consumption goods are financed through imperfectly indexed credit, the budget share of illiquid durable goods affects the impact of inflation on the real wage. These predictions are confronted with data from sixteen OECD countries. We find that high household indebtedness lowers the natural rate of unemployment and increases real and nominal wage rigidity.
\end{abstract}

JEL CLASSIFICATION: E24, J51, J64.

KEYWORDS: Illiquid durables, unemployment, wage rigidity, household debt.

\footnotetext{
*Department of Economics, Stockholm School of Economics, Box 6501, S-113 83 Stockholm, Sweden. Phone: +46-8 736 9260. Fax: +46-8 347818 .

** Department of Economics, University of Oslo, Box 1095 Blindern, 0317 Oslo, Norway. Phone: +4722855156 .

This paper is part of the research project "Unemployment, institutions and policy" at SNF-Oslo. Financial support from the Swedish Council for Research in the Humanities and Social Sciences is gratefully acknowledged. The paper has benefitted from presentations at the Industrial Institute for Economic and Social Research, London School of Economics, Stockholm School of Economics, the Trade Union Institute for Economic Research and Uppsala University. We thank Douglas Hibbs, Richard Jackman, Per Lundborg, Henry Ohlsson, John Sutton, Anders Vredin, and in particular Charlie Bean, for helpful comments and discussion.
} 


\section{Introduction}

Unemployment differs across countries. To some extent this can be explained by the fact that countries have different endowments and hence do not face exactly the same shocks. However, there is now a solid body of empirical research which suggests that countries have different long-run rates of unemployment. Similarly, the response of unemployment to real and nominal disturbances varies significantly. For example, within Europe the unemployment history of Spain appears to differ a lot from that of Switzerland, and the whole of Europe appears to be different from USA. (See e.g. Bean, Layard and Nickell (1986), Alogouskoufis and Manning (1988), and Layard, Nickell and Jackman (1991). Bean (1994a) is a recent survey.)

What causes this variation? The usual answers point to the differences in labor market institutions: Some countries support their unemployed for an extended period of time, and hence have more persistent unemployment. Some countries give more power to trade unions, and hence have more unemployment. Longer duration of labor contracts means that an increase in inflation has a stronger impact on real wages. And so on.

Here we shall argue that, while labor market institutions are important, factors outside

the labor market matter as well. More precisely we shall claim that the composition of consumption, in particular the budget share of illiquid durable goods such as houses and cars, has an impact on wages. Workers in Italy and Spain lead a different life from those in Switzerland and Sweden, and the contrast in lifestyle translates into measurable differences in the countries' unemployment histories.

It is well known that fixed costs of adjusting the consumption of durables should in principle affect people's preference for money lotteries. This insight goes back at least to Flemming (1969), and has been further developed by Dickinson and de Meza (1984) and by Grossman and Laroque (1990). The reason is that there is an interval of incomes such that a consumer will not sell his durable, and only adjust non-durable consumption. For incomes outside the interval, the consumer adjusts. Typically, the consumer will therefore be averse to fair gambles with small gains and losses, because only non-durables consumption will be affected. On the other hand, when the gain or loss is so large that durables will be adjusted, we might see risk seeking behavior. (In Figure 1 below, we have 
drawn a typical von Neumann-Morgenstern utility function for this problem.) Grossman and Laroque (1990) theoretically demonstrate that quite small fixed adjustment costs can make adjustments occur very infrequently, and can have a large impact on the demand for risky assets.

These effects are not just theoretical peculiarities. In the housing market, transaction costs are considerable. Sales taxes and brokerage fees frequently constitute between five and ten per cent of the house price (see OECD (1994, p. 67)). Even tenants face transaction costs if they want to move, e.g. costs of searching, inspecting and carrying out the removal. When rented accommodation is subsidized, as it has been in a number of countries, it can be difficult to find an acceptable place to move at all. Markets for other durables, such as used cars and stereos, also work poorly. Indeed, there is by now ample evidence that the illiquidity of durables profoundly affects individuals' consumption pattern and portfolio composition. ${ }^{1}$

For most people, the labor market is the most important lottery they participate in; should an employee request a high wage even if this raises the risk of becoming unemployed? If adjustment costs are important for financial portfolio decisions, there is every reason to think that they might affect behavior in the labor market as well. The purpose of this paper is to demonstrate how the amount of illiquid durable consumption and the level of transaction costs affect labor market outcomes. To this end, we build a simple formal model of a labor market in which workers own durables. We assume that wages are set to balance the gains from higher wages for employed workers against the increased risk of becoming unemployed.

The model provides us with the following main predictions. First, the natural rate of unemployment should be decreasing in illiquid durables consumption. The reason is quite simply that the utility loss associated with becoming unemployed is greater, the greater is the budget share of durables. The higher cost of losing the job induces wage moderation and hence lower unemployment.

\footnotetext{
${ }^{1}$ The empirical importance of fixed adjustment costs in understanding aggregate consumption dynamics was first studied by Mishkin (1976), and is convincingly documented by Bertola and Caballero (1990), Bar-Ilan and Blinder (1992), Caballero (1993) and Eberly (1994). For empirical evidence on the relationship between non-traded assets and financial portfolios, see e.g. Giraldi, Hamaui and Rossi (1993) and the references therein.
} 
Secondly, transaction costs and durables affect the real wage rigidity, as they affect both the marginal gain from higher wages and the utility loss from becoming unemployed. Our analysis suggests that wage rigidity is increasing in the budget share of durables. Incidentally, this observation also sheds some light on the debate about whether rational workers can have wage aspirations which affect their wage claims. Whereas e.g. Alogoskoufis and Manning (1988) and Layard, Nickell and Jackman (1991) see wage aspirations as the key to understanding the slow adjustment of real wages in Europe, Phelps (1992) argues that this hypothesis implies irrationality on the part of workers and should hence be rejected. As we emphasized in the precursor to this paper, Ellingsen and Holden (1995), illiquid durables provide a link between people's past expectations - which rationally determine their durable investments - and their current wage demands. Thus, our approach provides a microfoundation for the aspirations hypothesis.

Thirdly, we identify a rationale for nominal wage rigidity. In our model, nominal wage rigidity is caused by the (realistic) assumption that illiquid durables are financed through borrowing, and interest rates are imperfectly indexed to inflation. ${ }^{2}$ We argue that nominal wage rigidity should be increasing in the budget share of illiquid durables. Here, then, we have a new theory of why real wages are negatively related to changes in inflation (the short-run Phillips curve is not vertical), even if workers fully observe the parameters of the model and wages are adjusted instantaneously.

The predictions are tested using data from sixteen OECD countries. We argue that household indebtedness, measured as household debt divided by household disposable income, is a good measure of the budget share of illiquid durables. To our satisfaction, household indebtedness has the expected sign in all our regressions, and is both economically and statistically significant in accounting for differences in unemployment rates and nominal wage rigidity. Moreover, we argue that labor market conditions do not greatly affect differences in indebtedness. Hence we conclude that household indebtedness does help us to understand long-run unemployment as well as real and nominal rigidities.

Whereas we are aware of no previous work (except our own) which studies the link between consumption patterns and wage levels, economists have pointed out that the struc-

\footnotetext{
${ }^{2}$ In fact, the model even suggests a rationale for imperfect indexation.
} 
ture of the housing market might affect unemployment. Notably, Hughes and McCormick, in a series of papers on labor mobility in Britain, have found that home ownership and subsidized rental housing constitute barriers to regional migration and may therefore raise unemployment (see Hughes and McCormick (1987) and the references therein). We fully accept this proposition. We analyze a different relationship; how illiquid durable consumption affect the wage and unemployment levels within a region for a given level of migration (zero). In this case, an increase of transaction costs lowers unemployment by making it more costly to the workers (who therefore demand lower wages). Since the two effects go in opposite directions, it is an empirical matter to decide which one dominates. ${ }^{3}$ Another important difference between our work and that of Hughes and McCormick is that while they mainly emphasize the magnitude of the transaction costs, we are primarily concerned with the budget share of housing and other illiquid durables.

The rest of the paper is organized as follows. In section 2, we set out the basic model, which is analyzed in section 3 . Section 4 confronts the model with data, and section 5 concludes.

\section{Model}

We consider a trade union comprising $L$ workers, who are all equally productive. Denote the real wage by $W$ and let labor demand facing the union be denoted $N(\alpha, W)$, where $\alpha$ is a stochastic shift parameter measuring economy wide labor demand conditions. Hence

$$
u=(L-N(\alpha, W)) / L
$$

is the aggregate unemployment rate. We assume that a trade union chooses the real wage conditional upon $\alpha$. (This is just the standard monopoly union model.) The union maximizes the sum of its members utilities. Thus, the union faces a trade-off between high real wages $(W)$ and a low unemployment $(u)$. We are here interested in identifying the determinants of this choice. (The trade-off between real wages and the risk of becoming

\footnotetext{
${ }^{3}$ As noted below, we have done some work which indicates that home ownership correlate negatively with unemployment.
} 
unemployed is not particular to trade union models, and we believe that our central insights carry over to other institutional set-ups. The model is chosen in part for its tractability and in part because unions have empirically played an important role in wage setting in many countries.)

To facilitate computations, we shall work with a linear aggregate labor demand function, ${ }^{4}$

$$
N(\alpha, W)=\alpha-\alpha_{1} W
$$

We assume that $N=0$ for $W>\alpha / \alpha_{1}$. Laid off workers receive an income $B$. Whereas workers are assumed not to affect $B$ directly (i.e. the trade union treats $B$ as exogenous), we assume that in equilibrium

$$
B=B^{e}(\alpha)=b W(\alpha)
$$

with the replacement ratio $b \in(0,1)$. This assumption will imply that the consumption of laid off workers is positively correlated with the wage, and is meant to capture the fact that in reality laid off workers are not unemployed forever. ${ }^{5}$

Workers consume non-negative quantities of two kinds of goods; durable and nondurable. As durables, we consider goods which are consumed over a long period of time and is costly to adjust. The workers' utility of consumption is ${ }^{6}$

$$
U(C, D)=C^{1-\delta} D^{\delta}
$$

where $C$ is the quantity of non-durables, $D$ is the quantity of durables, and $\delta$ is a parameter between 0 and $b$. Consumption good prices are taken to be exogenous, and we

\footnotetext{
${ }^{4}$ While our results would go through for many other specifications, an iso-elastic labor demand would not do for our purposes as it tends to produce a wage which is independent of the shift parameter $\alpha$, cf. McDonald and Solow (1981).

${ }^{5}$ We think of our trade union as being one among many unions in the economy. While each union neglects the effect of its wage on the aggregate wage level, they jointly affect it, and it is this aggregate wage level which determines $B$.

${ }^{6}$ The Cobb-Douglas utility function is chosen for convenience. Whereas it is important for our results that the elasticity of substitution is not infinite, we believe this elasticity affects the magnitudes rather than the signs of our results.
} 
nomalize units so that both prices are initially equal to $1 .^{7}$ This formulation implies that any variation in the budget shares of durables must come through the taste parameter $\delta$. Due to our definition of durables, this parameter can however be interpreted quite broadly. For example, the consumption of owner occupied housing depends not only on factors which affect the tastes for housing, such as climate, but also on the relative price of owner occupancy to that of rented housing.

The model has five stages. At stage 1 each union member makes a durable goods decision, for example a choice of house. Except for the question of nominal rigidity, it does not matter whether the durable good is purchased or rented; the important assumption is that the decision cannot costlessly be reversed. To simplify the analysis of nominal rigidities, we assume that all workers purchase their durable, and that the purchase is financed by borrowing at a fixed nominal rate of interest, $r$. (We do not attempt to endogenize $r$.) At stage 1, the workers do not know the realization of labor demand (the parameter $\alpha$ ), and hence their income. Each worker chooses $D$ to maximize expected utility, and the choice is denoted $\bar{D}$. At stage 2, the labor demand parameter $\alpha$, is revealed. Then, at stage 3 , the rate of inflation is realized. ${ }^{8}$ At stage 4 , the (real) wage is determined and henceforth the number of unemployed workers. Finally, at stage 5, workers decide their consumption baskets subject to their budget constraints. A worker may decide to sell his durable good and reinvest, or he may stick with the original level. At each stage, everyone knows what has happened at earlier stages. For considerations of space, we do not include an analysis of stage 1 in the paper, and it is thus not necessary to specify workers' expectations concerning the labor demand parameter $\alpha .{ }^{9}$ Rather, we shall take $\bar{D}$ as given and focus on the implications for wages and employment of variation in $\alpha$, i.e. of ex post expectational errors, which inevitably tend to make $\bar{D}$ ex post inoptimal (at least for some workers).

We assume that the real interest rate is non-negative, i.e. $r \geq \pi$.

Crucially, there is a fixed transaction cost $T$ associated with altering the volume of

\footnotetext{
${ }^{7}$ Economy-wide shocks to labor demand would probably affect the relative price of durables. It is however not obvious in which way, and this effect is neglected in the following.

${ }^{8}$ Inflation is exogenous here. While it would be interesting to explore optimal monetary policies in a world with illiquid durable goods, that is a separate research topic.

${ }^{9}$ Such an analysis is given in Ellingsen and Holden (1995).
} 
durable goods chosen at stage 1 . We assume that $T$ is proportional to the value of the durable object, $T=t \bar{D}$. Workers differ in the transaction costs that they face, and we capture this in a simple fashion by letting $t$ take on two different values, $t \in\left\{t_{L}, t_{H}\right\}$, with $0<t_{L}<t_{H}$. The cost $t_{L}$ is set to be so low that it pays for the worker to adjust the durables consumption if he loses the job, whereas $t_{H}$ will be so high that it does not pay to adjust durables even when unemployed. Let $\lambda$ be the fraction of workers with transaction cost $t_{L} \cdot{ }^{10}$ To assure that each worker chooses the same amount of durable investment initially, we assume that at stage 1 workers do not know their future level of transaction costs. Note that we preclude the possibility that workers wait to purchase the durable good in order to avoid the transaction costs. We want to capture that, in the real world, there is ample time for shocks to disposable income after durable consumption goods are acquired. ${ }^{11}$

\section{Analysis}

We look for a subgame perfect equilibrium, and hence start at the last stage. From this point on we save notation by dropping all arguments on which a function depends, except when the function is first introduced and when it is evaluated at a particular point.

Let $M \in\{B, W\}$ denote real labor income, and let $Y$ denote disposable real income net of transactions costs, $T$, and including any capital gains, $H$. Thus

$$
Y= \begin{cases}Y^{K}=M & \text { if } D=\bar{D} \\ Y^{S}=M+H-T & \text { if } D \neq \bar{D}\end{cases}
$$

Define

$$
x=\frac{1+r}{1+\pi} .
$$

\footnotetext{
${ }^{10}$ We treat $\lambda$ as exogenous. In a sample of some 700 Norwegians who had been unemployed for more than six months, Colbjørnsen (1994) documents that about five per cent had chosen to sell their dwelling, and about ten per cent their car, due to their financially distressed situation.

${ }^{11}$ Alternatively we could have added another period of consumption to the model, so as to provide a more explicit rationale for purchasing the durable at stage 1 .
} 
A worker that keeps his durable good may then buy

$$
\bar{C}=Y^{K}-x \bar{D}
$$

units of the non-durable good, and thus obtains utility

$$
v^{K}\left(Y^{K}, \bar{D}\right)=\bar{C}^{1-\delta} \bar{D}^{\delta}
$$

A worker who sells the durable good and reinvests, obtains a real capital gain (or loss) of $H=\bar{D}(\pi-r) /(1+\pi)$ and thus gets a utility

$$
\begin{aligned}
v^{S}\left(Y^{S}\right) & =\max \left\{C^{1-\delta} D^{\delta} \mid C+D \leq Y^{S}, C \geq 0, D \geq 0\right\} \\
& =(1-\delta)^{1-\delta} \delta^{\delta} Y^{S}
\end{aligned}
$$

(This follows directly from the first-order conditions, which yield the solution $C=(1-$ $\delta) Y^{S}, D=\delta Y^{S}$.) Given an optimal reinvestment decision, a worker's utility is

$$
v(Y, \bar{D})=\max \left\{v^{K}, v^{S}\right\}
$$

We assume that the worker keeps the durable good if $v^{K}=v^{S}$.

Our simplifying assumption that there is only one consumption period, and that workers cannot postpone their purchase of durables, involves the complication that if the real interest rate is positive, those who adjust their consumption face a lower opportunity cost of durables and hence may have a greater utility of income than those who don't adjust. To avoid unnecessary confusion, we shall therefore evaluate our results at $x=1$ throughout. (On the other hand, we need to carry $x$ in our expressions in order to study the effects of a change in inflation.)

How does the worker's consumption choice depend on durable investment $\bar{D}$ and labor income $M$ ? Consider first variations in income for a given level of durable consumption. There exist two critical levels of labor income, denoted $M^{R}(\bar{D})$ and $M^{I}(\bar{D})$, for which the worker is indifferent between selling and keeping the durable good, i.e. $v^{K}\left(M^{R}\right)=$ $v^{S}\left(M^{R}+H-T\right)$ and $v^{K}\left(M^{I}\right)=v^{S}\left(M^{I}+H-T\right)$. As a convention, let $M^{I}>M^{R}$. The fact 
that there exist exactly two such values is a consequence of the following observations:

- $v^{K}$ is continuous and strictly concave in $Y^{K}$, while $v^{S}$ is continuous and linear in $Y^{S}$

- $v^{K}>v^{S}$ for $M=\bar{D} / \delta$,

- $v^{K}<v^{S}$ for $M=\bar{D}$ and for $M$ sufficiently large.

This is all very intuitive: For low income levels the worker will sell the initial holding of the durable and buy less (Reduce), for high income levels the worker will sell and buy more (Increase), while for medium income levels, it is best to keep the durable.

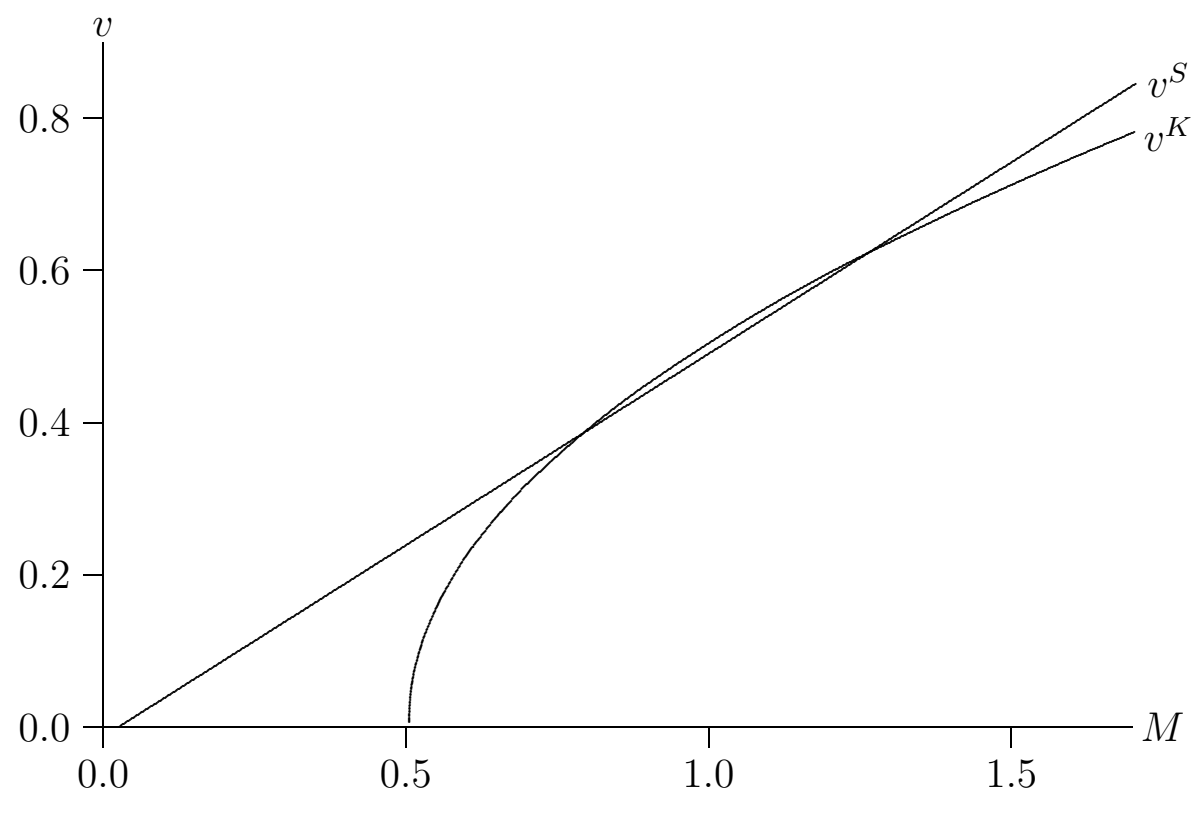

FiguRe 1

Figure 1 depicts $v^{K}$ and $v^{S}$ as functions of money income $M$ for a numerical example, with parameters $\delta=0.5, \bar{D}=0.5, t=0.05$. Recall that $v$ is the upper envelope of $v^{K}$ and $v^{S}$. Two features are worth noting. First, the interval of inaction is quite large; relative to the "ideal" income where $\bar{D}$ is optimal (which is $M=1$ in this example), it takes an income reduction of more than $17 \%$, or an increase of more than $22 \%$, in order to make the consumer incur the $5 \%$ transaction cost. Even for a $1 \%$ transaction cost, it takes a deviation of almost $9 \%$ from the ideal income to make the transaction worthwhile. Secondly, for income levels such that a worker chooses to sell, utility is linear in income, whereas if the workers keep their durable good, utility is a strictly concave function of income. 
The feature that utility is linear when workers sell is convenient for the interpretation of the model, as it ensures that any non-linearity of the utility function is due to the rigidities with respect to the consumption of illiquid durables. Moreover, $v^{K}$ is more concave the greater is the durables' budget share, $\delta$. Intuitively, when $\delta$ is large the relative impact on the consumption of non-durables from variations in income is large. Thus, the inoptimality of the composition of consumption tend to be more severe for any given departure of income from the ideal level.

In our analysis, we shall focus on situations in which labor market conditions are roughly what the workers expected them to be when they made their investments in durables. To capture this notion, let the equation

$$
x \bar{D}=\delta Y^{K}(\bar{D}, \bar{\alpha})
$$

define $\bar{\alpha}$, the value of the labor demand parameter which makes the initial quantity of the durable optimal ex post. Correspondingly, let the equation

$$
x D^{*}(\alpha)=\delta Y^{K}\left(D^{*}(\alpha), \alpha\right)
$$

define $D^{*}$, the quantity of the durable good which would have been optimal ex post given the labor demand parameter $\alpha$. We are going to study what happens for labor demand conditions in an interval close to $\bar{\alpha}$, and evaluate derivatives at $\alpha=\bar{\alpha}$. In particular, this means that the employed workers always choose to keep their durable good. (Ellingsen and Holden (1995) allow for larger shocks to $\alpha$.) Also, the indirect utility function has a particularly simple form. Since we are going to use the indirect utility function and its derivatives repeatedly, we have for reference reported them all in Table A1.

At this point, it is useful to derive explicitly the conditions on $t_{L}$ and $t_{H}$. For the unemployed with low transaction costs to sell rather than keep, we must have $v^{S}(B+$ $\left.H-T ; t_{L}\right)>v^{K}(B, \bar{D})$. Using our assumptions $B=b W$ and evaluating at $\alpha=\bar{\alpha}$ (i.e. $x \bar{D}=\delta W)$ this condition becomes $t_{L}<\hat{t}$ where

$$
\hat{t}=1-x+\frac{b x}{\delta}-\frac{1}{\delta}\left(\frac{(b-\delta) x}{1-\delta}\right)^{1-\delta}
$$


Correspondingly, we must have $t_{H} \geq \hat{t}$.

As all employed workers and a fraction $1-\lambda$ of the unemployed workers keep their durable good, the utilitarian union wants the wage which maximizes

$$
V=v^{K}(W)\left(\alpha-\alpha_{1} W\right)+\left[(1-\lambda) v^{K}(B)+\lambda v^{S}(B+H-T)\right]\left[L-\left(\alpha-\alpha_{1} W\right)\right] .
$$

Assuming that solutions are interior (i.e. there is some unemployment in equilibrium), the equilibrium wage, denoted $W^{*}$, satisfies the first-order condition

$$
\phi\left(W^{*}\right)=v_{W}^{K}\left(W^{*}\right)\left(\alpha-\alpha_{1} W^{*}\right)-\alpha_{1}\left[v^{K}\left(W^{*}\right)-(1-\lambda) v^{K}(B)-\lambda v^{S}(B+H-T)\right]=0 .
$$

We see that at the optimal wage, the utility gain for the employed workers of a marginal wage rise exactly balances the loss in utility for the workers that lose their job due to the wage rise. Below we shall make extensive use of equation (8) to analyze how the optimal wage $W^{*}$ depends on the parameters $\delta, \lambda$ and $\pi$. The second-order condition is of the form

$$
\phi_{W}\left(W^{*}\right)=v_{W W}^{K}\left(W^{*}\right)\left(\alpha-\alpha_{1} W^{*}\right)-2 \alpha_{1} v_{W}^{K}\left(W^{*}\right)<0 .
$$

Since $v_{W W}^{K}$ is non-positive and $v_{W}^{K}$ is positive, we see that the second-order condition is fulfilled.

Having characterized consumption and wage setting, we are now ready to derive the natural rate of unemployment as well as the amount of wage rigidity.

\subsection{The natural rate of unemployment}

We conveniently define the natural rate of unemployment as

$$
u^{N}=\left[L-N\left(\bar{\alpha}, W^{*}(\bar{\alpha})\right)\right] / L,
$$

i.e. the rate of unemployment resulting from the labor demand to which workers have adapted their consumption. ${ }^{12}$ Inserting $\bar{D}=D^{*}=\delta W^{*} / x$ into the first-order condition

\footnotetext{
${ }^{12}$ This definition neglects that $\bar{\alpha}$ may depend on $\delta$. Intuitively, it may be optimal for workers with large $\delta$ to choose a level of housing which is optimal at a relatively low value of $\alpha$ in order to "insure" against
} 
(8) and using equations (2), (3) and (4), we find the equilibrium wage

$$
W^{*}(\lambda, \bar{\alpha})=\frac{\bar{\alpha}}{\alpha_{1}\left[2-(1-\lambda)\left(\frac{b-\delta}{1-\delta}\right)^{1-\delta}-\lambda x^{\delta-1}\left(b x-\delta\left(x+t_{L}-1\right)\right)\right]}
$$

For the reason given above, we focus on the case in which $x=1$. The relationship between the real wage and the fraction of durables can then be stated as follows:

Proposition 1 The wage $W^{*}(\bar{\alpha})$ is decreasing in the share of durables in consumption. Proof: See Appendix.

Since unemployment is increasing in the real wage, we have the following corollary:

Corollary 1 The natural rate of unemployment is decreasing in the share of durables in consumption, i.e. $d u(\bar{\alpha}) / d \delta<0$.

The intuition behind this result is that the difference in utility between employed and unemployed is greater when durables are important. Recall that for $\alpha=\bar{\alpha}$, the employed consume an optimal bundle. Consider first the unemployed who keep, and hence consume a sub-optimal bundle. The sub-optimality becomes more severe when the proportional adjustment of non-durables is large, i.e. when durables constitute a large fraction of consumption. For the unemployed that sell their durable good, the argument is even simpler. Since transaction costs are increasing in the level of durables, the unemployed make a correspondingly larger loss.

An interesting issue is the role of $\lambda$ for the level of unemployment. It is quite straightforward to show that the wage, and hence the unemployment rate, is an increasing function of $\lambda$.

Proposition 2 The unemployment rate is an increasing function of the fraction of the workforce which has low transaction costs, i.e. $d u(\bar{\alpha}) / d \lambda>0$.

Proof: See Appendix.

The intuition is simple. Since an unemployed worker with low transaction costs is strictly better off than an unemployed worker with high transaction costs, the union's loss of negative income shocks. However, including this effect would only further strengthen our results. 
utility from added unemployment is smaller the larger is $\lambda$. Thus, a union with many "flexible" members will be less concerned with unemployment. Of course, this effect would be further amplified if unemployment could be concentrated among the flexible members.

Intuitive as this last result is, we note that the effect may be offset if the unemployed with low transaction costs move out of the region under consideration (and out of our model).

\subsection{Real wage rigidity}

Whereas the natural rate of unemployment captures how durables affect unemployment given that labor demand is at its normal level, $\bar{\alpha}$, durables also affect how unemployment reacts when labor demand deviates from this level. Real wage rigidity is a measure of the extent to which real wages "respond" to changes in unemployment. ${ }^{13}$

In our model, where all labor market shocks are to the parameter $\alpha$, wage rigidity can be measured as

$$
\rho(\bar{\alpha})=-\frac{d\left(u(\bar{\alpha}) / w^{*}(\bar{\alpha})\right)}{d \alpha}
$$

where $w^{*}=\ln W^{*}$. In other words, the index measures the change in the unemployment rate relative to the percentage change in the real wage. Using the definition of $u$, and saving on notation by dropping the argument $\bar{\alpha}$, we have

$$
\rho=-\frac{W^{*} d u / d \alpha}{d W^{*} / d \alpha}=-\frac{W^{*}\left(\alpha_{1} \frac{\partial W^{*}}{\partial \alpha}-1\right)}{L \frac{\partial W^{*}}{\partial \alpha}}
$$

Using (11), we have after a few manipulations

$$
\rho(\bar{\alpha})=1-u(\bar{\alpha})
$$

\footnotetext{
${ }^{13}$ Since wages and unemployment are both endogenous variables, this usage can be somewhat misleading, in particular in a static model such as ours. The time series evidence indicates that employment reacts faster to changes in the environment than wages do and it is this difference in speed that creates a positive measure of wage rigidity in the data; see e.g. Jacobsson, Vredin and Warne (1997).
} 
By Corollary 1 we know that $u(\bar{\alpha})$ is decreasing in $\delta$, so that $\rho(\bar{\alpha})$ is decreasing in $\delta$ : the influence of durables on real wage rigidity is positive. Likewise, by Proposition $2, u$ is increasing in $\lambda$, so it follows that $\lambda$ has a negative effect on $\rho$.

Proposition 3 Real wage rigidity, $\rho(\bar{\alpha})$, is increasing in the budget share of illiquid durables, $\delta$, and decreasing in the fraction of workers with low transaction costs, $\lambda$.

Thus, while a large budget share of durables keep unemployment levels down, we should also expect unemployment to be less sensitive to market conditions. This result is driven by consideration of the workers who remain employed after a labor market shock: If they spend much of their income on an illiquid durable, the marginal utility of income above $W^{*}(\bar{\alpha})$ is relatively low, and the marginal utility of income below $W^{*}(\bar{\alpha})$ is relatively high. Thus, the more illiquid durables, the less the employed workers appreciate a change in the wage.

Taken together, Propositions 1 and 3 indicate that we should be careful not to confuse a low natural unemployment rate with high real wage flexibility. Our theory says that the countries with the lowest natural rate of unemployment should have the highest real wage rigidity.

\subsection{Nominal wage rigidity}

So far, we have held inflation fixed. Recall that the rate of inflation is realized at stage 3, before the workers demand their real wage. Given that workers know the rate of inflation, will inflation still have an effect on the real wage? To see why the answer is affirmative, consider the utility of a worker who do not adjust his durable consumption, as expressed by equation (3). If the rate of inflation goes up, the real cost of paying for the durable goes down, as real income is transferred from lenders to borrowers (due to the fixed nominal interest rate).

Formally, the effect of inflation on wages is found by differentiating (8) to get

$$
\frac{d W^{*}}{d \pi}=\frac{\alpha_{1}\left[v_{\pi}^{K}\left(W^{*}\right)-\left(\lambda v_{\pi}^{S}(B+H-T)+(1-\lambda) v_{\pi}^{K}(B)\right)\right]-v_{W \pi}^{K}\left(W^{*}\right)\left(\alpha-\alpha_{1} W^{*}\right)}{v_{W W}^{K}\left(W^{*}\right)\left(\alpha-\alpha_{1} W^{*}\right)-2 \alpha_{1} v_{W}^{K}\left(W^{*}\right)} .
$$

The denominator is negative by the second-order condition, (9), and $v_{W \pi}^{K}\left(W^{*}\right)$ is also 
always negative. The latter effect reflects the fact that as inflation goes up, the employed workers' marginal utility of income decreases, which in turn leads to more moderate real wages. It remains to sign the term

$$
v_{\pi}^{K}\left(W^{*}\right)-\left(\lambda v_{\pi}^{S}(B+H-T)+(1-\lambda) v_{\pi}^{K}(B)\right) .
$$

The sign depends on the fraction of the unemployed who adjust their durable goods consumption. In the extreme case that $\lambda=1$ (all unemployed sell), we show in the appendix that if $r=\pi$, the term is zero at $\alpha=\bar{\alpha}$. Thus, the real wage is decreasing in inflation $\pi$. In the other extreme case, $\lambda=0$ (all unemployed keep), the same term is easily seen to be negative (just differentiate with respect to $\pi$ in equation (3)). The intuition is that inflation increases the utility of both employed and unemployed workers, but the unemployed gain more, because their marginal utility of increasing the consumption of non-durables is larger. This implies that the utility loss from becoming unemployed is decreasing in inflation, tending to increase wage pressure. Hence in this case there are two opposing effects. In the appendix, we show that the latter effect dominates at $\alpha=\bar{\alpha}$, i.e. the real wage is increasing in $\pi$. To summarize:

Proposition 4 The effect of inflation on the real wage $W^{*}(\lambda, \bar{\alpha})$ is ambiguous. In particular, if $x=1, W_{\pi}^{*}(1, \bar{\alpha})<0$ and $W_{\pi}^{*}(0, \bar{\alpha})>0$.

\section{Proof: See Appendix.}

At first sight, this result is quite remarkable. While inflation may lower the real wage, it is also theoretically possible that the real wage goes up (when no workers adjust their durables consumption). The key variable is $\lambda$. The higher is $\lambda$ the more will inflation depress the real wage; however, if $\lambda$ is sufficiently low, inflation will not depress wages at all. In numerical experiments, we generally find that $\lambda$ has to be below 0.1 before inflation will plausibly raise wages in our model. If unemployment was not random, but could be concentrated on groups with low transaction costs (youths, say), then $\lambda$ would have to be even lower. Thus, if we take the model seriously to the point of calibration, the prediction must be that inflation lowers the real wage.

How, then, does the budget share of durables affect the impact of inflation on the real wage? An immediate observation is that the effect of inflation goes to zero as the budget 
share of durables goes to zero.

Proposition $5 \lim _{\delta \rightarrow 0} d W^{*}(\lambda, \alpha) / d \pi=0$.

This is obvious from the fact that the only effect of inflation on the real wage comes through the purchase of durables at stage 1 . If $\delta=0$, no durables will be bought, and inflation has no effect. Furthermore it is easy to see that $d W^{*}(\alpha) / d \pi$ is a continuous function of $\delta$.

The analysis for $\delta>0$ is more complicated. In numerical experiments with equation (13), we have found cases in which the relative change in the real wage following a change in the rate of inflation is respectively monotonically increasing, monotonically decreasing, and non-monotonic in the share of durables. For example, if $\alpha=\bar{\alpha}, b=0.9, \lambda>0.1, \delta<$ 0.5 , numerical analysis reveals that $d W^{*} / d \pi<0$ and that $d^{2} W^{*} / d \delta d \pi<0$. We have yet to discover a "realistic" example in which and $d^{2} W^{*} / d \delta d \pi>0$. Thus, to the extent that our theory gives any guidance at all, it says that inflation should depress the real wage and that this effect should be stronger as the budget share of durables becomes larger.

Here we have taken for granted that debt contracts are nominal. Our theory hints at a reason for why the interest rate is in fact nominal. Suppose, realistically, that negative labor demand shocks are associated with high real interest rates. Then, net savers (capitalists, pensioners) gain from future high interest rates at the same time as net borrowers (workers) lose from current low wages. Even in the absence of risk aversion, illiquid durables means that the marginal utility of the winners is lower than that of the losers. Hence, there is potential scope for an insurance contract between the two. Of course, there is a variety of reasons (adverse selection and moral hazard) why individual workers cannot insure their real wages. Whereas there are collective unemployment insurance schemes, these do not take into account differences in illiquid durable consumption. Nominal interest rates are a substitute for a consumption based insurance scheme, in that it transfers income from the beneficiaries of high real interest rates to the losers. An accommodating monetary policy of course further strengthens this insurance effect of nominal interest rates. 


\section{Empirical Analysis}

In this section we study the effect of durables on the natural rate unemployment, and on real and nominal wage rigidity.

As a proxy for the consumption share of durables we have chosen household indebtedness, i.e. household debt as a fraction of disposable income. As an indicator of illiquid durables consumption household indebtedness has the advantage that it measures quite well how much money is left for non-durable expenditure - at least in the short run and if people own rather than rent the durables they consume. ${ }^{14}$

Our cross-section analysis is based on data for 16 OECD countries, indebtedness being measured in or around 1983. The indebtedness data are mainly taken from Kneeshaw (1995), who relies on reports from the central banks of thirteen countries. ${ }^{15}$ Data for an additional three countries (Denmark, Finland, and Norway) are from Berg (1994). For a few of the countries, there are substantial discrepancies between the numbers reported by Kneeshaw and those of other sources. For example, Japelli and Pagano (1989) who use official statistics to compute the sum of personal consumer loans and home mortgage loans for seven countries in the same period, report much lower figures for Italy and Spain than Kneeshaw does. ${ }^{16}$ Nevertheless, we have here chosen not to tinker with Kneeshaw's numbers. The only adjustment we have made is an upward revision for Denmark, because the 1983 figure is extremely low compared to surrounding years. (The revision turns out to be inconsequential for our results.) As shown in Table A2, there is considerable variation in indebtedness across countries. Three countries, Norway, Sweden, and Switzerland, play in a league of their own. The average household debt in these countries exceed one year's disposable income, whereas in Italy and Belgium, the indebtedness is less than a quarter

\footnotetext{
${ }^{14} \mathrm{~A}$ measure such as the home ownership ratio, which at first sight might look to be a reasonable measure of the consumption share of illiquid durables, but it is not. For example, the measure does not account for differences in house prices. As a curiosity, we mention that in cross-country data there is hardly any relationship between home ownership ratios and household indebtedness. Indeed, due to the high indebtedness and low ownership ratio in Switzerland, the relationship tend to be negative if anything.

${ }^{15}$ See Kneeshaw's Table 3. For most countries, total financial liabilities equal debt claims. Otherwise, we have used the former figure.

${ }^{16}$ Japelli and Pagano also report a lower figure for Japan, but acknowledge that this number may be downward biased. Indeed, the OECD figure for household liabilities in Japan is even higher than Kneeshaw's number.
} 
of this level.

Given that some of our dependent variables have been computed from time series of more than thirty years, one might worry that a single observation of the key explanatory variable is not a fair representation of its historical value. Can we be sure that a country with a relatively high household indebtedness in 1983, has had relatively heavily indebted households throughout the whole period? Unfortunately, we have been unable to construct long time series for this variable for each of the countries. However, Kneeshaw (1995) reports the variable for both 1983 and 1993 for his thirteen countries, and Berg reports a longer yearly time series for the remaining three. Regressing the 1993 value on the 1983 value gives us the following result,

$$
\text { Indebtedness }^{\prime} 93=13.37+1.06 \text { Indebtedness }^{\prime} 83 \quad \bar{R}^{2}=0.85 \text {. }
$$

This tells us that even after a decade of large changes in the operations of financial markets across the world, and huge swings in economic activity, the household indebtedness of each country in 1993 can be predicted rather well by the indebtedness in $1983 .{ }^{17}$ We would expect that the relationship is even more stable before 1983.

Apart from the indebtedness variable, information on all explanatory variables are taken from Layard, Nickell and Jackman (1991), and we refer to their book for detailed sources and definitions. (See the Appendix for exact references to their data tables.) These variables capture the key features of unemployment insurance, such as the duration of benefits and the ratio of benefits to past wages (the replacement ratio); the organization of the labor market, in particular the degree of organized coordination at each side of the market; as well as the duration and indexation of contracts. We report the values of the explanatory variables in Table A2 and of the dependent variables in Table A3.

\footnotetext{
${ }^{17}$ In fact, if we were to exclude Sweden, where a near collapse of property markets (and consequently credit markets) lead to an extreme 30\% decrease in household indebtedness between 1988 and 1993, the $R^{2}$ goes up to 0.90 , with the coefficient on Indebtedness' 83 being 1.16 rather than 1.06 .
} 


\subsection{The natural rate}

We first try to explain cross-country differences in the natural rate of unemployment. What is a good empirical measure corresponding to our $u(\bar{\alpha})$ ? There are at least three possible approaches. The first is to construct some underlying long run rate of unemployment (a "natural" rate) for each country from time series data. For this purpose, we have used a recent estimate provided by Bean (1994b), who studied a generalized fixed effects model of the kind

$$
\Delta f\left(u_{i t}\right)=\mu_{i}\left[\kappa_{i}+\beta_{i} \gamma_{t}-f\left(u_{i t-1}\right)\right]+\epsilon_{i t}
$$

where $\kappa_{i}$ is the country-specific fixed effect, $\gamma_{t}$ is a time-specific fixed effect whose impact differs across countries through $\beta_{i}, \mu_{i}$ is a parameter which allows the speed of adjustment to differ across countries, and $\epsilon_{i t}$ is an idiosynchratic error. Notice that if $\mu_{i}=1$, then $\kappa_{i}+\beta_{i} \gamma_{t}$ would be an estimate of $f\left(u_{i t}\right)$. Bean uses the functional form $f(u)=2\left(u^{0.5}-1\right)$, as this form appears to fit the data quite well.

Regressions (1) and (2) of Table 1 represent our best attempts to explain Bean's empirical estimate of $\hat{\kappa}_{i}$ (which in Bean is referred to as $\hat{\alpha}$ ). ${ }^{18}$ The explanatory power is remarkably high for cross-section regressions of this kind. ${ }^{19}$ Indebtedness has the expected sign and is here significant at the $1 \%$ level. (Dropping this variable from the regression would lower $\bar{R}^{2}$ to 0.71 in regression (2).) The other significant variables are union coordination, which tend to raise long-run unemployment, and employer coordination and corporatism which lower long-run unemployment. ${ }^{20}$ Neither benefit duration nor the replacement ratio seem to have any explanatory power for long-run unemployment.

The second approach is to look at the actual unemployment in some period during which there were no aggregate shocks, so that consumption may have had time to adjust. In regressions (3) and (4), the dependent variable is the average of the actual rate of unemployment in the relatively tranquil period between the two oil price shocks.

Finally, since we have indebtedness data for 1983, it is tempting to see how the re-

\footnotetext{
${ }^{18}$ We are grateful to Charlie Bean for sharing his numbers with us.

${ }^{19}$ We have also estimated a variety of equations including other variables, but these other variables tend to be statistically insignificant.

${ }^{20}$ Note that we use the Calmfors-Driffill measure of corporatism (LNJ's variable $C O R P^{\prime}$ ), whose value is low when wage setting is either very centralized or very decentralized and higher inbetween.
} 
TABLE 1: UnEMPLOYMENT

\begin{tabular}{|c|c|c|c|c|c|c|}
\hline \multirow{3}{*}{ Independent variables } & \multicolumn{6}{|c|}{ Dependent variable: Unemployment Rates } \\
\hline & \multicolumn{2}{|c|}{ "Natural" } & \multicolumn{2}{|c|}{ Actual 74-79 } & \multicolumn{2}{|c|}{ Actual $80-85$} \\
\hline & $(1)$ & $(2)$ & $(3)$ & $(4)$ & $(5)$ & $(6)$ \\
\hline Benefit duration & $\begin{array}{r}0.0001 \\
(0.02)\end{array}$ & & $\begin{array}{r}0.056 \\
(3.60)\end{array}$ & $\begin{array}{r}0.056 \\
(3.76)\end{array}$ & $\begin{array}{r}0.088 \\
(2.18)\end{array}$ & $\begin{array}{r}0.086 \\
(2.27)\end{array}$ \\
\hline Replacement ratio & $\begin{array}{r}0.0016 \\
(0.44)\end{array}$ & & $\begin{array}{r}0.015 \\
(1.23)\end{array}$ & $\begin{array}{r}0.017 \\
(1.43)\end{array}$ & $\begin{array}{r}0.094 \\
(2.92)\end{array}$ & $\begin{array}{l}0.100 \\
(3.35)\end{array}$ \\
\hline Union coordination & $\begin{array}{r}0.478 \\
(2.75)\end{array}$ & $\begin{array}{r}0.464 \\
(3.00)\end{array}$ & $\begin{array}{r}-0.700 \\
(1.20)\end{array}$ & $\begin{array}{r}-0.484 \\
(1.40)\end{array}$ & $\begin{array}{r}-1.43 \\
(0.94)\end{array}$ & \\
\hline Employer coordination & $\begin{array}{l}-0.714 \\
(5.53)\end{array}$ & $\begin{array}{l}-0.687 \\
(6.92)\end{array}$ & $\begin{array}{r}-1.682 \\
(3.85)\end{array}$ & $\begin{array}{r}-1.771 \\
(4.70)\end{array}$ & $\begin{array}{r}-3.395 \\
(3.00)\end{array}$ & $\begin{array}{r}-4.04 \\
(4.89)\end{array}$ \\
\hline Contract flexibility & $\begin{array}{l}-0.088 \\
(1.40)\end{array}$ & $\begin{array}{l}-0.082 \\
(1.47)\end{array}$ & $\begin{array}{r}0.100 \\
(0.47)\end{array}$ & & $\begin{array}{r}0.468 \\
(0.85)\end{array}$ & \\
\hline C-D corporatism & $\begin{array}{r}-0.051 \\
(2.48)\end{array}$ & $\begin{array}{l}-0.052 \\
(3.81)\end{array}$ & $\begin{array}{r}-0.301 \\
(4.39)\end{array}$ & $\begin{array}{r}-0.297 \\
(4.66)\end{array}$ & $\begin{array}{r}-0.21 \\
(1.16)\end{array}$ & $\begin{array}{r}-0.161 \\
(0.98)\end{array}$ \\
\hline Indebtedness & $\begin{array}{r}-0.0094 \\
(3.23) \\
\end{array}$ & $\begin{array}{r}-0.0094 \\
(3.63) \\
\end{array}$ & $\begin{array}{r}-0.044 \\
(4.39) \\
\end{array}$ & $\begin{array}{r}-0.045 \\
(4.79) \\
\end{array}$ & $\begin{array}{r}-0.059 \\
(2.31) \\
\end{array}$ & $\begin{array}{r}-0.056 \\
(2.46) \\
\end{array}$ \\
\hline $\bar{R}^{2}$ & 0.83 & 0.86 & 0.85 & 0.86 & 0.77 & 0.79 \\
\hline
\end{tabular}

"Natural" is Bean's empirical estimate of $\kappa_{i}$. Constants are not reported. Number of observations: 16 . t-values in parentheses.

gressions look in the rather more turbulent period 1980-85. What we have not done is to investigate the post-1990 experience. The reason is that while we know indebtedness for 1993, the values of several of the other explanatory variables have changed considerably since the early eighties. And since some of these variables have been constructed in quite elaborate ways, we are unable to make a credible update ourselves.

Indebtedness remains statistically significant (at the $5 \%$ level) in all regressions. And, more importantly, it is also economically significant. A rough measure of economic significance is the effect on unemployment from changing an independent variable from a 
"low" value to a "high" value. ${ }^{21}$ Table 2 shows the number of percentage points change in the unemployment implied by the parameter estimates in column (1), (3), and (5) of Table 1.

Table 2: Change in Unemployment

\begin{tabular}{lccr}
\hline \hline & \multicolumn{4}{c}{ Change, percentage points } \\
From a change in & Long run & Act. 74-79 & Act. 80-85 \\
\hline Benefit duration & 0.0 & 2.4 & 3.7 \\
Replacement ratio & 0.0 & 0.6 & 3.8 \\
Union coordination & 0.9 & -1.4 & -2.9 \\
Employer coordination & -2.8 & -3.4 & -6.8 \\
Contract flexibility & 0.4 & 0.4 & 1.9 \\
C-D corporatism & -0.7 & -4.3 & -2.9 \\
Indebtedness & -1.8 & -3.4 & -4.4 \\
\hline \hline
\end{tabular}

In interpreting these numbers, one should keep in mind that the long-run unemployment figures computed by Bean tend to range from one to four per cent (essentially representing the pre-1973 experience), whereas the actual unemployment 1974-79 was in the $5-7.5 \%$ range for several countries and had risen much further in the next five years. The table shows that, regardless of how we define it, unemployment is considerably lower in countries with high household indebtedness. Only employer coordination appears consistently to matter more to the unemployment figures. ${ }^{22}$

Given the strong results, one might be worried about misspecification of our regressions. First, is it possible that indebtedness is affected by unemployment; a high level

\footnotetext{
${ }^{21}$ This is more interesting than reporting elasticities, because independent variables can have rather different variances. Our choice of high and low values for the explanatory variables can be found in the Appendix (bottom of Table A2).

${ }^{22}$ It is interesting that union coordination, which tend to increase unemployment in the long run, appears to lower unemployment in the period 1974-85. This may suggest that well-coordinated unions acted responsibly after the first oil-price shock.
} 
of unemployment could make workers more reluctant to bind up consumption illiquid durables? To check this, we perform a Hausman test. The test fails, by a broad margin, to reject our hypothesis that indebtedness is exogenous; the t-value on the instrument for indebtedness ranges from 0.06 in regression (1) to 0.81 in regression (5). ${ }^{23}$ Second, what about omitted variable bias? It is quite clear that indebtedness is affected by the business cycle in much the same way as is labor demand. Do regressions (3)-(6) in Table 1 suffer from the fact that indebtedness in 1983 is driven by the same forces that drive unemployment 1974-85? Since we do not have sufficient data on indebtedness, the only way to test for this is somehow to remove the country specific shock component from the unemployment data. We have done this by using Bean's econometric model to estimate what each country's average unemployment would have been in the period 1974-89 for the average value of $\gamma_{t}$. Even in this case indebtedness in 1983 is statistically and economically significant at around the levels reported above.

We conclude that the prediction of Corollary 1 appears to be supported by the data.

Proposition 2 suggests that unemployment is higher when transaction costs are lower, although we have warned that the effect of transaction costs on migration may go in the opposite direction. Given that housing is the main durable good, one approach to empirical measurement is to include data on home ownership in our unemployment regressions. ${ }^{24}$ When we have done so, home ownership tends to enter with a negative sign, as predicted by Proposition 2, but the results are not statistically significant. ${ }^{25}$ (The result is not sensitive to the inclusion of the Indebtedness variable.) This finding contrasts starkly with Oswald's (1996) widely published claim that home ownership tends to raise unemployment. ${ }^{26}$ The main difference, it seems to us, is that Oswald bases his

\footnotetext{
${ }^{23} \mathrm{As}$ usual, the instrument variable was constructed by regressing indebtedness on all the other exogenous variables. We have not been able to locate data on any independent financial variable which could plausibly instrument for indebtedness. (Indeed, it is our belief that climate is probably a better candidate; rough climate makes for better houses.) Thus, we refrain from attempting to run any two-stage least squares regressions.

${ }^{24}$ Hughes and McCormick (1987) summarize some of the evidence for the UK. They report that, ceteris paribus, there is considerably lower mobility among home owners than among workers who rent on the private market.

${ }^{25}$ We do not report the full analysis here as it requires a detailed discussion of the appropriate home ownership data.

${ }^{26}$ E.g., a recent update of Oswald's cross-country regression was reported, diagram included, in The Economist June 14th 1997, p94.
} 
cross-country analysis on univariate regressions. The change of sign is due simply to the inclusion of such variables as employer coordination and union coordination in the regressions.

\subsection{Real rigidity}

How does the workers' demand for real wages respond to changes in labor demand? An empirical estimate of this effect is obtained by Layard, Nickell and Jackman (1991, ch.9, Table 2). We emphasize that such estimates may not be very precise, and should be taken with a pinch of salt. For an illustration of this point, see Jacobson et al. (1997). Table 3 reports some of the more interesting regressions, the dependent variable being the inverse of LNJ's flexibility estimate $\bar{\gamma}_{1}$.

According to Proposition 3, real wage rigidity should be increasing in indebtedness. The regressions reveal that indebtedness has the expected sign. Evaluating a change from low to high levels (as above), we find that the magnitude of its effect on wage rigidity is comparable to that of union coordination and corporatism. However, the effect is not statistically significant at conventional levels.

Plotting wage rigidity against indebtedness (Figure 2), we might suspect that the fit is destroyed by three or four countries; Japan, Norway, Switzerland and Sweden. All these have very low measures of real wage rigidity, and in particular the latter three have high household indebtedness.

How can we account for the simultaneous occurrence of high indebtedness and low real rigidity in the three countries? One guess is that omitted variables, such as layoff costs, geographical factors or industry structure, may account for the outliers. ${ }^{27}$ Another is that real wage rigidity has not been measured correctly. In particular there is a suspicion that wage rigidity in Norway and Sweden has been underestimated due to failure to account properly for the effect of hefty devaluations. The recent experience of high unemployment in Sweden, when (for the first time in 20 years) price stability took priority over short term employment after a major negative labor demand shock, suggests that there may be

\footnotetext{
${ }^{27}$ Although there is a variety of measures of layoff costs, we have not been able to compile comparable data for all 16 countries, except on the proportion of people with tenured employment. This variable is statistically insignificant in the regressions we have run.
} 
Table 3: Real Wage Rigidity

\begin{tabular}{|c|c|c|}
\hline \multirow[b]{2}{*}{ Independent variables } & \multicolumn{2}{|c|}{ Real rigidity } \\
\hline & (1) & $(2)$ \\
\hline Benefit duration & $\begin{array}{r}0.022 \\
(3.45)\end{array}$ & $\begin{array}{r}0.022 \\
(3.74)\end{array}$ \\
\hline Replacement ratio & $\begin{array}{r}-0.0010 \\
(0.19)\end{array}$ & \\
\hline Union coordination & $\begin{array}{r}-0.260 \\
(1.06)\end{array}$ & $\begin{array}{r}-0.252 \\
(1.11)\end{array}$ \\
\hline Employer coordination & $\begin{array}{r}-0.344 \\
(1.88)\end{array}$ & $\begin{array}{r}-0.356 \\
(2.21)\end{array}$ \\
\hline Contract flexibility & $\begin{array}{r}0.101 \\
(1.14)\end{array}$ & $\begin{array}{r}-0.097 \\
(1.19)\end{array}$ \\
\hline $\mathrm{C}-\mathrm{D}$ corporatism & $\begin{array}{r}-0.057 \\
(1.95)\end{array}$ & $\begin{array}{r}-0.055 \\
(2.09)\end{array}$ \\
\hline Indebtedness & $\begin{array}{r}0.0063 \\
(1.53)\end{array}$ & $\begin{array}{r}0.0062 \\
(1.61)\end{array}$ \\
\hline $\bar{R}^{2}$ & 0.46 & 0.52 \\
\hline
\end{tabular}

Real rigidity is the inverse of Layard, Nickell and Jackman's (1991) empirical estimate of $\bar{\gamma}_{1}$. Constants are not reported. Number of observations: 16 . $t$-values in parentheses.

something to this view.

\subsection{Nominal rigidity}

The impact of changes in inflation on wage setting has also been estimated by Layard, Nickell and Jackman (1991, ch.9, Table 2), who call this parameter $\bar{\gamma}_{2}$. Table 5 reports some of our regressions with $\bar{\gamma}_{2}$ as the dependent variable. ${ }^{28}$

\footnotetext{
${ }^{28} \mathrm{LNJ}$ have for some reason chosen only to report positive values of the rigidity parameters, and hence their Table 2 contains zeroes for six countries. As Proposition 4 shows, our theory does not imply that an increase in inflation must lower the real wage. Fortunately, it is straightforward to compute the true value of $\bar{\gamma}_{2}$ for all countries from LNJ ch.9 Table A3, and we have done so here.
} 


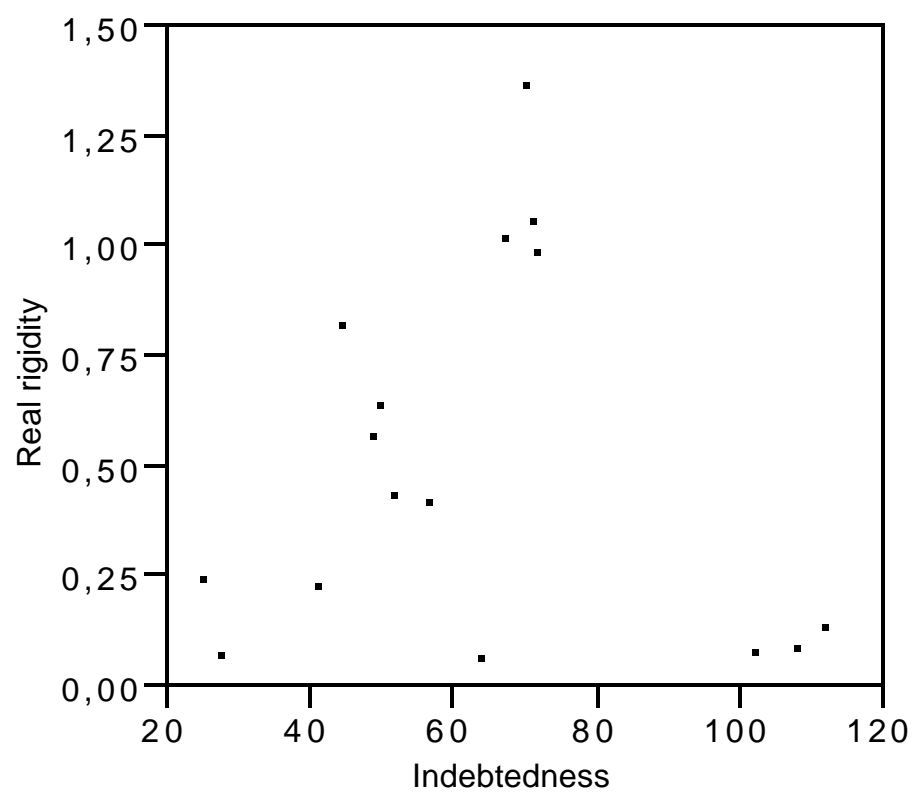

FiguRE 2

Whereas indebtedness performs better than any other variable, and we can explain almost $50 \%$ of the variance, Canada is a severe outlier. Excluding Canada from the sample not only improves the overall fit of the regressions, but also dramatically increases the $\mathrm{t}$-value of indebtedness. On the other hand, benefit duration does not seem to affect nominal rigidity at all.

Thus, our results suggest that nominal rigidity is mainly determined by indebtedness. In countries with high household debt, an increase in inflation tends to reduce the real wage, as we would expect if at least some unemployed workers adjust their durable consumption. More frequent contracting also tends to reduce the nominal rigidity. However, the effect is never statistically significant at the $5 \%$ level. ${ }^{29}$ Comparing the economic significance of indebtedness with that of contract renewal, we see from the parameter estimates in regressions (2), (5) and (6) that indebtedness is at least twice as important. ${ }^{30}$ These results suggest that nominal contracting in the labor market may not be the main explanation for nominal wage rigidity. Nominal contracting in the credit market appears

\footnotetext{
${ }^{29}$ Other measures of indexation and synchronization used by LNJ are completely insignificant and therefore we have omitted them from the regressions that we report.

${ }^{30}$ Recall that the contract renewal index lies between 0 and 2 , and indebtedness lies roughly between 25 and 110.
} 
Table 5: Nominal Wage Rigidity

\begin{tabular}{|c|c|c|c|c|c|c|}
\hline \multirow{3}{*}{ Independent variables } & \multicolumn{6}{|c|}{ Dependent variable: Nominal rigidity } \\
\hline & \multicolumn{3}{|c|}{ Canada included } & \multicolumn{3}{|c|}{ Canada excluded } \\
\hline & $(1)$ & $(2)$ & $(3)$ & $(4)$ & (5) & $(6)$ \\
\hline Benefit duration & & $\begin{array}{r}-0.029 \\
(1.34)\end{array}$ & $\begin{array}{r}-0.037 \\
(2.03)\end{array}$ & & & $\begin{array}{r}-0.005 \\
(0.30)\end{array}$ \\
\hline Replacement ratio & & $\begin{array}{r}0.023 \\
(1.36)\end{array}$ & $\begin{array}{c}0.021 \\
(1.26)\end{array}$ & & $\begin{array}{r}0.017 \\
(1.55)\end{array}$ & $\begin{array}{r}0.017 \\
(1.51)\end{array}$ \\
\hline Contract renewal & & $\begin{array}{r}-0.408 \\
(0.78)\end{array}$ & & & $\begin{array}{r}-0.605 \\
(2.09)\end{array}$ & $\begin{array}{r}-0.553 \\
(1.58)\end{array}$ \\
\hline Indebtedness & $\begin{array}{c}0.043 \\
(3.23)\end{array}$ & $\begin{array}{r}0.028 \\
(1.96)\end{array}$ & $\begin{array}{c}0.029 \\
(2.06)\end{array}$ & $\begin{array}{r}0.046 \\
(5.14)\end{array}$ & $\begin{array}{r}0.038 \\
(4.40)\end{array}$ & $\begin{array}{r}0.037 \\
(3.78)\end{array}$ \\
\hline $\bar{R}^{2}$ & 0.39 & 0.46 & 0.48 & 0.64 & 0.72 & 0.69 \\
\hline
\end{tabular}

Nominal rigidity is Layard, Nickell and Jackman's empirical estimate of $\bar{\gamma}_{2}$. Constants are not reported. Number of observations: 16 when Canada is included. t-values in parentheses.

to be more important.

Given that the effect of inflation on employment is due to imperfectly indexed credit in our model, it would be interesting to make a cross--country comparison of the contract terms of household credit. Ceteris paribus, nominal wage rigidity should be negatively related to the adjustability of interest rates. Regrettably, it has not been possible to get hold of relevant data. Borio (1995) has recently made an attempt to collect data on credit contracts in fourteen OECD contries, but he has only been able to obtain information on current conditions. In many European countries, the deregulation of financial markets means that current debt contracts tell us very little about the contractual terms facing these households in the fifties, sixties, and seventies.

\section{$5 \quad$ Final remarks}

The above results indicate that household indebtedness has a significant impact on unemployment and wage rigidity, and there is reason to believe that the relationship is due 
to the consumption of illiquid durables.

At a general level, our results indicate that the causes of unemployment are not all to be found within the labor market itself. Even in a unionized labor market such as the one depicted here, factors outside the labor market may affect the utility of the trade union's members and hence the union's behavior. Likewise, the effectiveness of policies to bring down unemployment, such as an expansionary monetary policy, may depend crucially on factors wholly outside the labor market.

Two caveats are in order. First, the theory is highly stylized. It is a partial equilibrium model, populated by workers who differ only in their transaction costs, and labor market institutions are taken as given. If we think of preferences and technology as being exogenous, it is quite possible that a richer model could generate predictions about trade unions' position on such institutional issues as seniority rules and replacement ratios. Strict seniority rules would in turn affect the durables investment of young and old workers. Secondly, we study evidence from a relatively small number of countries. The results should therefore be interpreted carefully, and it would be valuable to confront the theory with regional data from within a country. It would also be interesting to investigate whether the labor market behavior of individual workers depends on their consumption pattern.

Finally, we think our paper raises a number of new questions. One avenue for research is to examine government policies in light of our theory. For example, have monetary policies been more accommodating in countries with high household indebtedness?

\section{Appendix}

Here follows some computations, proofs and data tables.

\subsection{The indirect utility functions}

For easy reference we here tabulate the indirect utility functions and their derivatives, both in general and evaluated at $\alpha=\bar{\alpha}$. 


\begin{tabular}{lll}
\hline \hline & \multicolumn{1}{c}{ General } & \multicolumn{1}{c}{ At $\alpha=\bar{\alpha}$} \\
\hline & \multicolumn{1}{c}{$(W-x \bar{D})^{1-\delta} \bar{D}^{\delta}$} & $(1-\delta)^{1-\delta}(\delta / x)^{\delta} W$ \\
$v^{K}(W)$ & $(B-x \bar{D})^{1-\delta} \bar{D}^{\delta}$ & $(b-\delta)^{1-\delta}(\delta / x)^{\delta} W$ \\
$v^{K}(B)$ & $(1-\delta)^{1-\delta} \delta^{\delta}\left(B+\left(1-x-t_{L}\right) \bar{D}\right)$ & $(1-\delta)^{1-\delta} \delta^{\delta}\left(b+\left(1-x-t_{L}\right) \delta / x\right) W$ \\
$v^{S}(B+H-T)$ & $(1-\delta)^{1-\delta}(\delta / x)^{\delta}$ \\
$v_{W}^{K}(W)$ & $(1-\delta)(W-x \bar{D})^{-\delta} \bar{D}^{\delta}$ & $-(1-\delta)^{-\delta} \delta(\delta / x)^{\delta} W^{-1}$ \\
$v_{W W}^{K}(W)$ & $-\delta(1-\delta)(W-x \bar{D})^{-\delta-1} \bar{D}^{\delta}$ & $(1-\delta)^{-\delta} \delta(\delta / x)^{1+\delta}(d x / d \pi)$ \\
$v_{W \pi}^{K}(W)$ & $\delta(1-\delta)(W-x \bar{D})^{-\delta-1} \bar{D}^{1+\delta}(d x / d \pi)$ & $-(1-\delta)^{1-\delta} \delta^{\delta}(\delta / x)(d x / d \pi) W$ \\
$v_{\pi}^{S}(B+H-T)$ & $-(1-\delta)^{1-\delta} \delta^{\delta} \bar{D}(d x / d \pi)$ & $-(1-\delta)(b-\delta)^{-\delta}(\delta / x)^{\delta+1}(d x / d \pi) W$ \\
$v_{\pi}^{K}(B)$ & $-(1-\delta)(B-x \bar{D})^{-\delta} \bar{D}^{\delta+1}(d x / d \pi)$ & \\
\hline \hline
\end{tabular}

\subsection{Proofs}

Proof of Proposition 1: We need to show that the denominator of equation (11), call it $J$, is increasing in $\delta$. After a slight manipulation we have

$$
\frac{\partial J}{\partial \delta}=\lambda x^{\delta-1} Q(x)+\frac{1-\lambda}{(1-\delta)((b-\delta) /(1-\delta))^{\delta}} R(b)
$$

where

$$
Q(x)=t_{L}+x-1-\ln (x)\left((b-\delta) x+\left(1-t_{L}\right) \delta\right)
$$

and

$$
R(b)=1-b+(b-\delta) \ln ((b-\delta) /(1-\delta))
$$

Since $1>b>\delta$ a sufficient condition is that $Q(x) \geq 0$ at $x=1$ and that $R(b) \geq 0$ for all $b>\delta$, with at least one strict inequality. At $x=1, Q(x)=t_{L}>0$. It remains to show that $R(b) \geq 0$. This follows from the observation that $R(1)=0$, and

$$
R^{\prime}(b)=\ln \left(\frac{b-\delta}{1-\delta}\right)<0
$$

Proof of Proposition 2: We need to show that $W^{*}$ is increasing in $\lambda$. From equation 
(11) we see that $d W^{*} / d \lambda>0$ if and only if

$$
\left(\frac{b-\delta}{1-\delta}\right)^{1-\delta}>x^{\delta-1}\left(b x-\delta\left(x+t_{L}-1\right)\right)
$$

This condition is easily seen to be equivalent to the condition that unemployed workers with low transaction costs sell their durable good, i.e. the condition that $t_{L}<\hat{t}$.

Proof of Proposition 4: First, let us prove that $W_{\pi}^{*}(1, \bar{\alpha})<0$. As explained in the text, a sufficient (but not necessary) condition is that

$$
v_{\pi}^{K}\left(W^{*}\right)-\left(\lambda v_{\pi}^{S}(B+H-T)+(1-\lambda) v_{\pi}^{K}(B)\right) \geq 0
$$

or, since $\lambda=1$ in this case, that

$$
v_{\pi}^{K}\left(W^{*}\right)-v_{\pi}^{S}(B+H-T) \geq 0
$$

To simplify notation, let $x=(1+r) /(1+\pi)$ so that

$$
H=\frac{\bar{D}(\pi-r)}{(1+\pi)}=(1-x) \bar{D}
$$

Now, recall from (3) that

$$
v^{K}\left(W^{*}\right)=(W-x \bar{D})^{1-\delta} \bar{D}^{\delta}
$$

and, from (4) that

$$
v^{S}(B+H-T)=(1-\delta)^{1-\delta} \delta^{\delta}\left(B+\left(1-x-t_{L}\right) \bar{D}\right)
$$

Differentiation with respect to $\pi$ and evaluation at $\bar{D}=D^{*}=\delta W^{*} / x$ yields

$$
v_{\pi}^{K}\left(W^{*}\right)=-(1-\delta)^{1-\delta}(\delta / x)^{1+\delta} W^{*} \frac{d x}{d \pi}
$$

and

$$
v_{\pi}^{S}(B+H-T)=-(1-\delta)^{1-\delta} \delta^{\delta}(\delta / x) W^{*} \frac{d x}{d \pi} .
$$


When $r=\pi, x=1$, and thus $v_{\pi}^{K}\left(W^{*}\right)=v_{\pi}^{S}(B+H-T)$, completing the proof that $W_{\pi}^{*}(1, \bar{\alpha})<0$.

It remains to prove that $W_{\pi}^{*}(0, \bar{\alpha})>0$. As the denominator in (13) is negative, we have to show that the numerator is also negative when $\lambda=0$. If $\lambda=0, x=1$, and $\bar{D}=\delta W^{*}$, the numerator can be written as

$$
\phi=\alpha_{1} \delta\left(1-\left(\frac{1-\delta}{b-\delta}\right)^{\delta}\right) W^{*}+\frac{\delta^{2}}{1-\delta} N\left(W^{*}\right)
$$

Inserting from (11) and simplifying, we have

$$
\operatorname{sgn} \phi=\operatorname{sgn} \tau
$$

where

$$
\tau(b)=1-\left(\frac{1-\delta}{b-\delta}\right)^{\delta}+\frac{\delta}{1-\delta}\left(1-\left(\frac{b-\delta}{1-\delta}\right)^{1-\delta}\right) .
$$

We first prove that $\tau$ is increasing in $b$. Differentiation reveals

$$
\frac{\partial \tau}{\partial b}=\frac{\delta(1-\delta)}{(b-\delta)^{2}}\left(\frac{1-\delta}{b-\delta}\right)^{\delta-1}-\frac{\delta}{1-\delta}\left(\frac{b-\delta}{1-\delta}\right)^{\delta}
$$

and it is a matter of simple manipulations to show that

$$
\begin{aligned}
\operatorname{sgn} \frac{\partial \tau}{\partial b} & =\operatorname{sgn}\left[\frac{1-\delta}{(b-\delta)^{2}}\left(\frac{1-\delta}{b-\delta}\right)^{\delta-1}-\frac{1}{1-\delta}\left(\frac{1-\delta}{b-\delta}\right)^{\delta}\right] \\
& =\operatorname{sgn}\left[\frac{1-\delta}{(b-\delta)^{2}}-\frac{1}{1-\delta} \frac{1-\delta}{b-\delta}\right] \\
& =\operatorname{sgn}(1-b),
\end{aligned}
$$

which is positive as $0<b<1$. Observe also that $\tau(1)=0$. Hence $\tau(b)<0$ for all $b<1$. This completes the proof that $W^{*}(0, \bar{\alpha})$ is increasing in $\pi$.

\subsection{Data tables}

Below are the data on explanatory and dependent variables for each of the sixteen countries in our sample. 
TABle A2: Explanatory VARiables

\begin{tabular}{lrrrrrrrr}
\hline \hline Countries & $\begin{array}{r}\text { Ben. } \\
\text { dur. }\end{array}$ & $\begin{array}{l}\text { Rep. } \\
\text { ratio }\end{array}$ & $\begin{array}{c}\text { Union } \\
\text { coord. }\end{array}$ & $\begin{array}{c}\text { Empl. } \\
\text { coord. }\end{array}$ & $\begin{array}{r}\text { Cont. } \\
\text { flex. }\end{array}$ & $\begin{array}{c}\text { C-D } \\
\text { corp. }\end{array}$ & Indebt. & $\begin{array}{r}\text { Cont. } \\
\text { renew. }\end{array}$ \\
Belgium & 48 & 60 & 2 & 2 & 4 & 14 & 25.2 & 2 \\
Denmark & 30 & 90 & 3 & 3 & 6 & 2 & 49.0 & 2 \\
France & 45 & 57 & 2 & 2 & 3 & 16 & 41.2 & 1 \\
Germany & 48 & 63 & 2 & 3 & 4 & 9 & 71.9 & 2 \\
Italy & 6 & 2 & 2 & 1 & 4 & 11 & 27.7 & 0 \\
Netherlands & 48 & 70 & 2 & 2 & 5 & 13 & 51.7 & 2 \\
Spain & 42 & 80 & 2 & 1 & 5 & 16 & 44.3 & 1 \\
UK & 48 & 36 & 1 & 1 & 2 & 12 & 67.1 & 2 \\
Australia & 48 & 39 & 2 & 1 & 6 & 17 & 70.2 & 2 \\
Canada & 6 & 60 & 1 & 1 & 2 & 4 & 56.6 & 1 \\
USA & 6 & 50 & 1 & 1 & 1 & 5 & 71.0 & 0 \\
Japan & 6 & 60 & 2 & 2 & 4 & 10 & 63.8 & 2 \\
Finland & 58 & 75 & 3 & 3 & 3 & 8 & 50.0 & 1 \\
Norway & 18 & 65 & 3 & 3 & 4 & 2 & 108.0 & 1 \\
Sweden & 14 & 80 & 3 & 3 & 4 & 3 & 102.4 & 1 \\
Switzerland & 12 & 70 & 1 & 3 & 0 & 6 & 111.8 & 0 \\
\hline & & & & & & & & \\
"High" & 48 & 80 & 3 & 3 & 6 & 16 & 100.0 & 2 \\
"Low" & 6 & 40 & 1 & 1 & 2 & 2 & 25.0 & 0 \\
\hline \hline
\end{tabular}

The following independent variables are taken from LNJ ch.9 Table 7: Benefit duration, Replacement ratio, Employer coordination, Union coordination, and the Calmfors-Driffill corporatism index C-D corp $\left(=C O R P^{\prime}\right.$ in LNJ). The variable referred to here as Contract flexibility is defined as the sum of LNJ's indices of synchronization of wage contracts ( $S W C$; higher the more synchronization), wage indexation ( $I W$; higher with more indexation) and contract renewal ( $L W C$; higher for shorter contract duration) and can be computed from LNJ ch.9 Table 11. LNJ does not report the value for Spain. Like Bean (1994b) we have set it equal to 5 . Our Contract renewal variable is simply $L W C$. Data on indebtedness is from Kneeshaw (1995) and Berg (1994).

In selecting "high" and "low" values for the variables we have tried not to give excessive weight to outliers. 
Table A3: Dependent Variables

\begin{tabular}{|c|c|c|c|c|c|}
\hline Countries & $\kappa$ & $\begin{array}{c}\text { Actual } \\
\text { unemp. } \\
74-79\end{array}$ & $\begin{array}{c}\text { Actual } \\
\text { unemp. } \\
80-85\end{array}$ & $\begin{array}{c}\text { Real } \\
\text { rigidity }\end{array}$ & $\begin{array}{l}\text { Nominal } \\
\text { rigidity }\end{array}$ \\
\hline Belgium & 1.37 & 6.3 & 11.3 & 0.25 & -1.94 \\
\hline Denmark & 1.40 & 5.5 & 9.3 & 0.57 & 0.13 \\
\hline France & 61 & 4.5 & 8.3 & 0.23 & 0.27 \\
\hline Germany & 0.79 & 3.2 & 6.0 & 0.99 & 0.24 \\
\hline Italy & 2.20 & 4.6 & 6.4 & 0.08 & -0.56 \\
\hline Netherlands & 1.32 & 5.1 & 10.1 & 0.44 & -0.59 \\
\hline Spain & 1.76 & 5.3 & 16.6 & 0.83 & 1.07 \\
\hline UK & 1.31 & 5.1 & 10.5 & 1.02 & 0.00 \\
\hline Australia & 1.43 & 5.0 & 7.6 & 1.37 & -0.22 \\
\hline Canada & 2.20 & 7.2 & 9.9 & 0.42 & 4.28 \\
\hline USA & 2.18 & 6.7 & 8.0 & 1.06 & 1.08 \\
\hline Japan & 1.09 & 1.9 & 2.4 & 0.07 & 0.02 \\
\hline Finland & 1.31 & 4.4 & 5.1 & 0.65 & 0.39 \\
\hline Norway & 1.06 & 1.8 & 2.6 & 0.09 & 3.78 \\
\hline Sweden & 1.23 & 1.5 & 2.4 & 0.08 & 3.57 \\
\hline Switzerland & 0.10 & 1.0 & 1.7 & 0.14 & 1.72 \\
\hline
\end{tabular}

The variable definitions and sources are:

- $\kappa$ is a transformation of the long run rate of unemployment as estimated by Bean (1994b). This is the "natural" rate we explain in Table 1. To compute the implied long run rate of unemployment, apply the formula $u=(\kappa / 2+1)^{2}$.

- Actual unemployment 74-79 and 80-85 are the average unemployment rates in the years 1974-1979 and 1980-1985 respectively, as reported in Layard, Nickell and Jackman (1991, ch 9 Table 1).

- Real rigidity is defined as $1 / \bar{\gamma}_{1}$, where $\gamma_{1}$ is obtained from Layard, Nickell and Jackman (1991, ch 9 Table 2).

- Nominal rigidity is defined as $\bar{\gamma}_{2}$, as computed by Layard, Nickell and Jackman (1991, ch 9 Table 2 and Table A3). 


\section{References}

Alogoskoufis, George S. And Alan Manning (1988): On the Persistence of Unemployment, Economic Policy, 7, 428-469.

Bar-Ilan Avner And Alan S. Blinder (1992): Consumer Durables: Evidence on the Optimality of Doing Nothing, Journal of Money, Credit and Banking, 24, 253272.

Bean, Charles R. (1994a): European Unemployment: A Survey, Journal of Economic Literature, 32, 573-619.

Bean, Charles R. (1994b): European Unemployment: A Retrospective, European Economic Review, 38, 523-534.

Bean, Charles R., Richard Layard, and Stephen Nickell (1986): The Rise in Unemployment: A Multi-Country Study, Economica, Supplement, 53(S), S89-S120.

Berg, Lennart (1994): Household Savings and Debts: The Experience of the Nordic Countries, Oxford Review of Economic Policy, 10, 42-53.

Bertola, Guiseppe and Ricardo J. Caballero (1990): Kinked Adjustment Costs and Aggregate Dynamics, in:Olivier J. Blanchard and Stanley Fischer 8eds.): NBER Macroeconomics Annual 1990, Cambridge MA: MIT Press.

Borio, Claudio E.V. (1995): The Structure of Credit to the Non-Government Sector and the Transmission Mechanism of Monetary Policy: A Cross-Country Comparison, Bank for International Settlements, Working paper no. 24.

Caballero, Ricardo (1993): Durable Goods: An Explanation for Their Slow Adjustment, Journal of Political Economy, 101, 351-384.

Colbuørnsen, Tom (1994): Fra Elendighetsbeskrivelse til Mestringsstudier, in Perspektiv på Arbeidsløsheten, SNFs Årbok, Bergen: Fagbokforlaget.

De Meza, David and Paul T. Dickinson (1984): Risk Preferences and Transaction Costs, Journal of Economic Behavior and Organization, 5, 223-236. 
Eberly, Janice (1994): Adjustment of Consumers' Durables Stocks: Evidence from Automobile Purchases, Journal of Political Economy, 102, 403-436.

Ellingsen, Tore And Steinar Holden (1995): Sticky Consumption and Rigid Wages, Working Paper No. 62, Department of Economics, Stockholm School of Economics. Forthcoming in Brakman, van Ees and Kuipers (eds.): Market Behavior and Macroeconomic Modelling, Basingstoke: Macmillan.

Flemming, J.S. (1969): The Utility of Wealth and the Utility of Windfalls, Review of Economic Studies, 36, 55-66.

Giraldi, Claudio, Rony Hamaui and Nicola Rossi (1993): Non-Marketable Assets and Households' Portfolio Choices: A Case Study of Italy, Journal of Banking and Finance, 17, 1171-1190.

Grossman, Sanford J. And Guy Laroque (1990): Asset Pricing and Optimal Portfolio Choice in the Presence of Illiquid Durable Consumption Goods, Econometrica, $58,25-51$.

Hughes, Gordon And Barry McCormick (1987): Housing Markets, Unemployment and Labor Market Flexibility in the UK, European Economic Review, 31, 615-645.

Jacobson, Tor, Anders Vredin And Anders Warne (1997): Common Trends and Hysteresis in Scandinavian Unemployment, European Economic Review forthcoming.

Jappelli, Tullio, And Marco Pagano (1989): Consumption and Capital Markets Imperfections: An International Comparison, American Economic Review, 79, 1088 1105.

Kneeshaw, J.T. (1995): A Survey of Non-Financial Sector Balance Sheets in Industrialised Countries: Implications for the Monetary Policy Transmission Mechanism, Bank for International Settlements, Working paper no. 25.

Layard, Richard, Stephen Nickell and Richard Jackman (1991): Unemployment: Macroeconomic Performance and the Labor Market, Oxford: Oxford University Press. 
McDonald, Ian M. And Robert M. Solow (1981): Wage Bargaining and Unemployment, American Economic Review, 71, 896-908.

Mishkin, Frederic (1976): Illiquidity, Consumer Durable Expenditure and Monetary Policy, American Economic Review, 66, 642-654.

OECD (1994): Jobs Study. Evidence and Explanation, Part II: The adjustment potential of the labor market. Paris: OECD.

Oswald, ANDREw (1996): A Conjecture on the Explanation for High Unemployment in the Industrialized Nations: Part I, mimeo, December 1996, University of Warwick.

Phelps, Edmund S. (1992): A Review of Unemployment, Journal of Economic Literature, 30, 1476-1490. 